\title{
Análise da utilização de estratégias de marketing experiencial por uma marca de vestuário brasileira
}

\section{Analysis of the use of experiential marketing strategies by a Brazilian clothing brand}

\author{
João Henriques de Sousa Júnior Doutorando em Administração, Universidade Federal de Santa Catarina \\ (PPGAdm/UFSC), Brasil - sousajunioreu@hotmail.com
}

\begin{abstract}
RESUMO
O cenário competitivo global e o advento da tecnologia proporcionaram mudanças significativas no mercado e nos consumidores. Dentre essas mudanças, a conscientização, por parte das organizações, de que os novos consumidores não se satisfazem apenas com produtos e serviços, mas buscam, também, vivenciar experiências com as marcas. Dessa forma, o marketing experiencial vem ganhando força e notoriedade nos mais diversos segmentos, dentre eles o mercado de vestuário. Diante do exposto, o presente estudo busca analisar as estratégias do marketing de experiência utilizadas pela empresa Reserva, conhecida marca de vestuário brasileiro. Para tanto, foi realizada uma coleta de dados secundários a partir das postagens das mídias digitais da empresa selecionada. Os resultados obtidos a partir da análise do conteúdo coletado evidenciam a utilização nítida e estimulada do marketing experiencial pela marca na sua relação com os consumidores, com preocupação quanto à ideologia de novo conceito de vida e consumo de sentidos e significados que diferenciam os produtos da marca dos seus concorrentes.
\end{abstract}

Palavras-chave: Marketing de experiência. Estratégia de Marketing. Vestuário Brasileiro.

\begin{abstract}
The global competitive landscape and advances in technology have brought significant changes to the market and to consumers. Among these changes is the awareness of organizations regarding the new consumers that are not only satisfied with products and services, but also seek to have experiences with brands. In this context, experiential marketing has been gaining strength and notoriety in the most diverse segments, among them the clothing market. In view of the above, the present study seeks to analyze the marketing strategies used by the company Reserva, a well-known Brazilian clothing brand. For that, a secondary data collection was performed from the digital media postings of the selected company. The results obtained from the analysis of the collected content show clear and stimulated use of experiential marketing by the brand in its relationship with consumers, with concerns about the ideology of a new concept of life consumption of meanings and significances that differentiate branded products of their competitors.
\end{abstract}

Keywords: Marketing Experience. Marketing Strategy. Brazilian Clothing.

Recebido em 12/04/2019. Aprovado em 26/04/2019. Avaliado pelo sistema double blind peer review. Publicado conforme normas da APA. http://dx.doi.org/10.22279/navus.2020.v10.p01-11.957 


\section{INTRODUÇÃO}

As diversas transformações no cenário mundial, ocorridas ao longo das últimas décadas, tais como o advento da internet e tecnologias web e a globalização, impulsionaram mudanças tanto no mercado quanto nas sociedades. Dessa forma, a relação tradicional existente entre empresas e consumidores passou a ser mais diversificada. Hoje em dia, por exemplo, as relações de mercado podem ser realizadas de forma B2C (Businessto-Consumer) - entre empresa e consumidor, B2B (Business-to-Business) - entre duas empresas, e C2C (Consumer-to-Consumer) - entre dois consumidores.

Para além desta remodelação dos mercados, os consumidores também mudaram e, principalmente, graças às redes sociais virtuais eles estão cada vez mais informados, ativos e críticos. Assim, a área do marketing, impactada por essas mudanças, precisou sofrer transformações e adaptações para continuar desempenhando o seu papel essencial de obtenção de lucro a partir da compreensão dos anseios e desejos dos consumidores, do estímulo de suas necessidades e antecipação de tendências (Sousa Júnior et al., 2018).

Em seus trabalhos, Prahalad e Ramaswany (2000) e Sousa Júnior et al. (2018) retratam a importância das empresas compreenderem a adoção dos papéis desses novos consumidores, que deixaram de ser meros receptores de informações e serviços e passaram a estar, cada vez mais, envolvidos com todo o processo de produção e consumo dos bens e serviços. Assim, Prahalad e Ramaswany (2000) enfatizam que as organizações precisam ampliar o seu investimento na área de marketing de relacionamento, principalmente no que diz respeito à promoção de maior interação e fidelização dos consumidores a partir de experiências que lhes sejam únicas e de vivências subjetivas, identificando, dessa forma, o marketing experiencial.

A importância do olhar empresarial para as experiências dos consumidores já era um tema abordado por Holbrook e Hirschamn (1982), em que os autores afirmavam a necessidade que havia no mercado para que as empresas buscassem compreender e analisar o comportamento dos consumidores frente a expectativas, satisfação, prazer e experiências. É notório que as empresas buscam proporcionar experiências positivas em seus clientes, principalmente quando analisadas as estratégias de diferenciação e posicionamento de marca, mas o conceito de marketing experiencial tende a ser visto, tanto na academia quanto no mercado, como uma estratégia mais assertiva no que diz respeito à concretização das vendas e da fidelização dos clientes para com as organizações.

Dessa forma, algumas marcas de vestuário brasileiras já apresentam essa tendência de vender a seus clientes muito mais do que peças de roupas, mas, principalmente, experiências e consumo capazes de serem identificadas e representadas como um verdadeiro estilo de vida para a sociedade. Sousa Júnior et al. (2018) apontam que as estratégias de marketing de experiência são capazes de personificar as marcas, de tal forma que elas passam a ter voz, cheiro, filosofia e ideologia de vida.

Neste cenário, a presente pesquisa busca analisar as estratégias de marketing de experiência adotadas pela marca de vestuário brasileira Reserva. Este estudo se justifica através da busca de melhor compreensão e aprofundamento acerca da temática da estratégia mercadológica, a partir da utilização do marketing experiencial, uma vez que é uma temática em ascensão nos debates acadêmicos e de mercado, principalmente por ser compreendido como um grande diferencial competitivo mercadológico, e visa contribuir com o avanço deste tema analisando-o em ambiente de vestuário, uma vez que a maioria das pesquisas nesta área o relaciona ao ambiente do serviço.

\section{FUNDAMENTAÇÃO TEÓRICA}

Neste capítulo são apresentados os temas que embasaram esta pesquisa, a partir de uma revisão de literatura. Sendo estes: marketing, estratégias de marketing, marketing de experiência, e o setor de vestuário no Brasil. 


\subsection{Marketing}

Diversos autores apresentam diferentes conceitos acerca do marketing, porém, o mais aceito - em nível global - é da Associação Americana de Marketing (American Marketing Association - AMA, 2019) que o define como uma função organizacional e um conjunto de processos que envolvem a criação, comunicação e entrega de valor para os clientes, bem como para a gestão do relacionamento com eles, de modo que beneficie a organização e seu público-alvo.

Corrobora com essa definição o entendimento de Mesquita (2018) de que o marketing consiste de uma série de estratégias, técnicas e práticas cujo principal objetivo é o de agregar valor a determinadas marcas e produtos, e cuja finalidade é a de atribuir maior importância dessas empresas para um determinado grupo de consumidores.

Kotler e Keller (2012), por sua vez, compreendiam o marketing como a área responsável por identificar e satisfazer as necessidades humanas e sociais, identificando-o como uma das principais ferramentas para a obtenção de sucesso de qualquer organização, de qualquer área, em qualquer lugar do mundo. Enquanto Cobra (2011) acredita que o marketing deveria ser visto como uma filosofia, uma vez que estabelece uma norma de conduta para a empresa em que as necessidades dos consumidores devem definir as características dos produtos ou serviços a serem elaborados com as respectivas quantidades a serem oferecidas.

Neste século, mais do que nunca, as empresas precisam estar atentas tanto ao que acontece dentro delas - ambiente interno - quanto aos seus consumidores e concorrentes, sejam estes grandes ou pequenos - ambiente externo -, pois é essa análise dos ambientes que incentiva as organizações (Bezerra, 2012). Por este motivo, os profissionais de marketing, que lidam diretamente com o composto de marketing (Produto, Preço, Praça e Promoção) estão cada dia mais se utilizando de estratégias e ferramentas que o auxiliem na compreensão do mercado, dos seus consumidores (atuais e pontenciais) e na inovação e desenvolvimento de novos produtos e serviços que atendam às necessidades de seus clientes.

\subsubsection{Estratégias de marketing}

Todas as organizações necessitam de um planejamento eficaz e uma sólida estratégia de marketing para conseguir atingir suas metas e objetivos e, assim, lograr o sucesso (Ferrel \& Hartline, 2006). Esse pensamento é corroborado por Silva Junior, Vieira e Feitosa (2012) quando os autores afirmam que as organizações começaram a entender o seu funcionamento não de forma isolada no ambiente mercadológico e começaram a refletir sobre si próprias para adaptarem-se a um mundo de constantes mudanças. No que tange ao marketing, Mattos (2011) afirma que essa revolução renovou as formas de comunicação, publicidade e propaganda.

Tratando-se, especificamente, das estratégias de marketing, Kotler e Keller (2012) compreendem-as como a chave para a obtenção dos objetivos organizacionais, sendo consideradas eficazes as empresas que conseguem criar, entregar e comunicar a seus mercados-alvo produtos e serviços de modo mais efetivo e eficiente do que seus concorrentes. Nesse sentido, Ferrel e Hartline (2006, p. 12) apontam que "a estratégia descreve o plano de competição da organização para o sucesso", enquanto que "o marketing eficaz requer um sólido planejamento estratégico nos vários níveis de uma organização".

É interessante ressaltar que, na atual conjuntura mercadológica, os consumidores estão cada vez mais ativos e críticos, com mais voz e engajamento, podendo compartilhar uma variedade de sentimentos e informações uns com os outros, sobre um número inacreditável de bens, serviços e marcas, e isso faz com que as empresas busquem se adaptar a essa nova realidade (Kozinetz, 2010).

Diante destas informações, a última década tem mostrado um grande avanço mercadológico no que diz respeito à conquista e fidelização de clientes por parte das empresas, e isso se deve à utilização de diversas estratégias adotadas nos mais variados segmentos de mercado. Dentre essas novas estratégias, surge o conceito de propor aos consumidores uma vivência de experiência na aquisição de um bem ou serviço, perpassando o ato da compra em si. 


\subsubsection{Marketing de experiência}

A mudança da comercialização impulsionou uma evolução no conceito de marketing, distinta em três grandes períodos, de acordo com Las Casas (2009). A saber, este autor aponta que a primeira era do marketing estava direcionada à produção, uma vez que existia alta demanda e pouca oferta de produtos; mais adiante, o segundo momento foi identificado como a era das vendas e acontece após o período da revolução industrial, o que favorece o aumento excessivo de ofertas em contrapartida a uma diminuição potencial das demandas, fazendo surgir os estoques; por fim, o terceiro momento estaria aplicado à era, propriamente, do marketing, em que as organizações começaram a enxergar os clientes com outros olhos, tentando agradá-lo a fim de fidelizá-los, colocando-o como foco das organizações. Autores como Kotler e Keller (2012) apontam que o mundo já está vivenciando outra era, direcionada ao marketing digital.

As transformações de mercado ocorridas ao longo do tempo também impulsionaram uma evolução do pensamento do marketing e do comportamento do consumidor. Dessa forma, fica evidente o quanto o ambiente influencia nas organizações, e vice-versa, de tal forma que as organizações começaram a se adequar aos desejos e necessidades dos seus clientes, cada vez mais ativos e críticos (Prahalad \& Ramaswany, 2000). Assim, pesquisas como a de O'Shaughnessy e O'Shauhnessy (2002) começaram a enfatizar que, na realidade, os indivíduos não consomem apenas de forma racional, mas, também, com base em suas referências, experiências, expectativas emocionais e prazer.

A partir dessa constatação, os profissionais de marketing passaram a valorizar e instigar os indivíduos ao consumo com estratégias de utilização de referências, expectativas, prazer e experiência (Sousa Júnior et al., 2018) e foi dessa forma que foi se construindo o conceito do marketing experiencial ou marketing de experiência.

Schimitt (1999) já apontava que a utilização da experiência no marketing tem como finalidade propor valores e sensações de comportamento nos clientes, e, por isso, anos mais tarde, Poulsson e Kale (2004) enfatizaram a importância de que os consumidores vivenciem experiências que sejam tão tocantes ao ponto de serem consideradas únicas e pessoais.

No marketing de experiência os clientes consomem bens e serviços não apenas por atributos funcionais, mas, também, por suas características hedônicas e representações do significado que lhe é atribuido pelos consumidores e pela sociedade (Barbosa et al., 2011), por estes motivos que o consumo, sob a ótica do marketing de experiência, está relacionado às várias significações simbólicas que o produto ou serviço desperta no consumidor (Schimitt, 1999; Sousa Júnior et al., 2018).

Holbrook (2000) trata de como o consumidor toma decisões a partir do seu imaginário e das expectativas, emoções e hedonismo que possui, mas, o novo consumidor não quer vivenciar uma simples situação de compra, ele quer mais, ele busca experiências cada vez mais consideradas como extraordinárias, ou seja, ele anseia vivenciar situações que ultrapassam o tradicional ao qual ele já está habituado a encontrar em outras lojas ou ambientes de compra (Gupta \& Vajic, 2000; Barbosa et al., 2011).

Apesar de ser um tema ainda incipiente nos estudos acadêmicos, é possível identificar a utilização do marketing experiencial em empresas de diversos segmentos de mercado, desde entretenimento à moda, por exemplo. Sobre este último segmento é que se detêm o próximo tópico deste estudo.

\subsection{O Setor de Vestuário no Brasil}

Segundo o Instituto de Estudos de Marketing Industrial - IEMI (2012), o Brasil é um dos maiores produtores de vestuário do mundo, sendo responsável por 2,6\% das toneladas de roupas fabricadas no mercado mundial. Em 2018, conforme a Associação Brasileira da Indústria Têxtil (ABIT, 2018), o setor apresentou crescimento em produção e investimentos.

Apesar do momento de crise financeira no mercado brasileiro, os indicadores mais recentes de pesquisas realizadas pelo IEMI (2018) apontam que houve um aumento de $24,6 \%$ no volume de vendas no varejo brasileiro de vestuário, quando analisados os meses de fevereiro e março de 2018. Além disso, o mês de março de 2018 teve um volume de produção de 473,608 milhões de peças produzidas, sendo 2,975 milhões 
destas direcionadas à exportação, o que representou um aumento de $23,2 \%$ quando comparado ao mês de março de 2017 (IEMI, 2018).

Não o bastante, o próprio estudo do IEMI (2018) destaca que o varejo de moda brasileiro está em transformação e busca valorizar ainda mais os desejos e necessidades dos diversos segmentos de consumidores. Dessa forma, faz-se importante compreender estratégias de marketing experiência neste mercado que apresenta expansão e transformações.

Apresentados os temas que norteiam este trabalho de pesquisa, o próximo capítulo apresentará o percurso metodológico do trabalho, bem como apresentará um pouco mais detalhada a história e característica de cada empresa selecionada para análise.

\section{PROCEDIMENTOS METODOLÓGICOS}

Esta pesquisa apresenta caráter exploratório e foi estruturada em duas partes, sendo a primeira uma revisão bibliográfica em que a discussão foi sustentada a partir do marketing de experiência e o setor de vestuário no Brasil; em um segundo momento, foi realizada uma coleta de dados secundária, a partir das mídias digitais de uma marca de vestuário brasileiro, selecionada por indicar o uso de estratégias do marketing experiencial nas campanhas de seus produtos, para uma análise do conteúdo propagado por ela.

A escolha da empresa de vestuário Reserva se deu de acordo com a utilização da mesma quanto ao marketing de experiência na promoção de sua marca e a abrangência de atuação no mercado nacional, além da sua alta atividade e geração de conteúdo em seus perfis nas redes sociais virtuais.

A coleta dos dados foi realizada entre os meses de janeiro a março de 2019 , sendo estes coletados a partir dos conteúdos postados no websitee redes sociais oficiais da empresa. Para fins de comprovação quanto à descrição da experiência vivenciada pelos clientes, foram observados os feedbacks dados pelos usuários seguidores das páginas através de comentários postados nesses mesmos perfis.

\subsection{A Reserva}

A marca 'Reserva' tem início em 2004, quando dois amigos cariocas, dentro de uma academia de ginástica, notaram vários homens usando exatamente o mesmo modelo de bermuda, e perceberam ali uma demanda de mercado reprimida. Diantes deste fato, os amigos criaram a sua própria bermuda e, a parti daí, deram início à Reserva - nome dado em homenagem à praia preferida da turma (Reserva, 2019a).

Dois anos depois da sua criação, a empresa participou da semana de moda carioca - a Fashion Rio e abriu a primeira loja, em Ipanema-RJ. No site, a empresa define que "enquanto o mercado buscava um lifestyle específico, a Reserva se posicionava como amigo e não como marca" (Reserva, 2019a).

Depois do São Paulo Fashion Week e da chegada da marca à capital paulista, a marca lançou a sua segmentação infantil, a Reserva Mini, seu e-commerce, e a submarca Eva. Não o bastante, os incentivos em marketing digital fizeram com que o engajamento do público com a marca se tornasse uma realidade virtual, sendo a Reserva a primeira marca de moda brasileira a alcançar o expressivo número de quase dois milhões de fãs na rede social Facebook (Reserva, 2019a).

Atualmente, a marca atua em todo o Brasil, sendo o grupo Reserva composto por 1.580 (mil quinhentas e oitenta) pessoas divididas em suas três marcas a partir de suas 65 lojas próprias nas principais capitais do Brasil, oito franquias e presença em 1.400 (mil e quatrocentas) lojas multimarcas pelo país (Reserva, 2019a).

Sob o slogan de que "ser feliz nunca sai de moda", a Reserva apresenta-se aos seus consumidores como uma família, ressaltando, principalmente, suas propostas de cultura e experiência do consumidor para com a marca (Reserva, 2019a). 


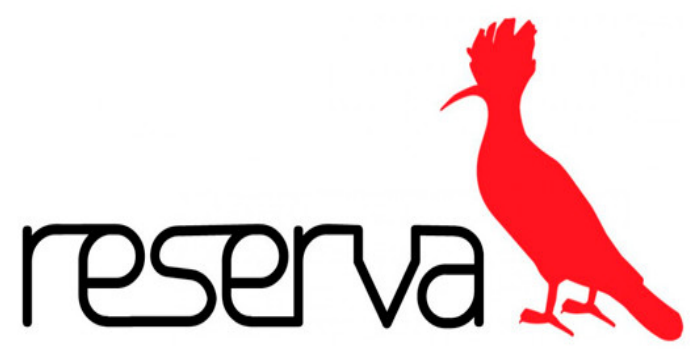

Figura 1- Logomarca Reserva Fonte: Reserva (2019a).

A ideia da logo da Reserva, que é uma sombra do pássaro Pica-Pau, se deu a partir de um encontro com o lixo. Isso porque, segundo informações do portal MeuSucesso.com (2016), enquanto estavam na busca por algum símbolo que representasse a empresa, um dos amigos fundadores da marca, não animado com as propostas que lhes foram apresentadas, questionou a designer sobre desenhos que já tivessem sido rejeitados, assim, quando a designer trouxe o lixo, no topo estava o desenho da sombra do Pica-Pau, que despertou o interesse imediado dos sócios e acabou se tornando não apenas o logotipo que estampa as peças de roupa da marca, mas também se tornou uma referência no mercado de vestuário brasileiro (Meusucesso.com, 2016).

\section{ANÁLISE E DISCUSSÃO DOS RESULTADOS}

Após conhecer um pouco sobre a história e características da empresa selecionada para compor o exemplo deste estudo, foi feita uma análise dos registros e publicações nas suas principais redes (website Facebook e Instagram) a fim de constatar as estratégias que cada uma apresenta utilizando o marketing de experiência.

A Reserva adota estratégias experienciais de forma bastante ativa, principalmente através de frases e textos incisivos. Em seu site, por exemplo, é perceptível a abordagem da campanha atual, onde eles destacam a importância da sustentabilidade através do uso do marketing verde. Mas, para além da promoção desta imagem sustentável, a empresa apresenta um posicionamento focado em passar ao consumidor a imagem de empresa acolhedora - tal como uma família - e reforça isso no decorrer das suas postagens nas mídias sociais digitais.

Apresentando-se como uma organização de cultura forte, a empresa se vende como uma marca capaz de proporcionar experiências inesquecíveis aos seus consumidores, através de seus produtos. Dessa forma, em seu site, a empresa destaca ao leitor/consumidor que as palavras-chave para a organização são 'cultura', 'família' e 'experiência', como pode ser observado na Figura 2.

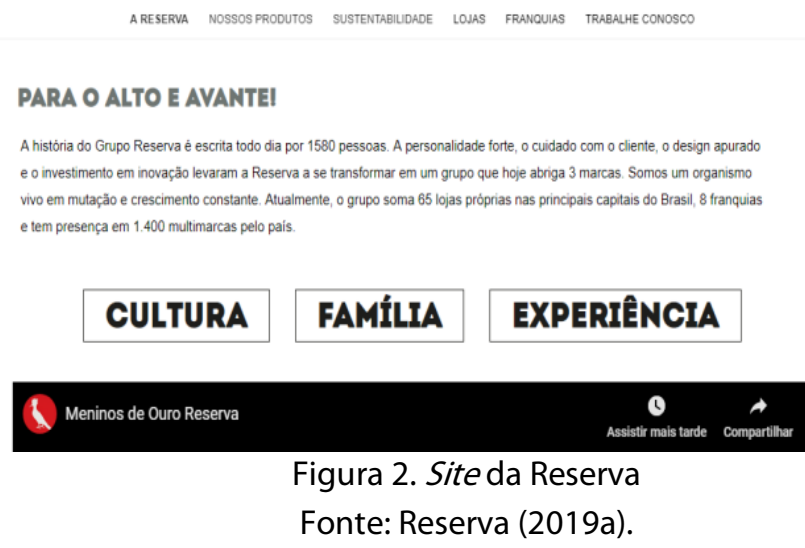


Quando o usuário do site clica no link da palavra 'experiência' ele é direcionado a uma página em que a empresa agrupou vídeos, imagens e frases que retratam os relatos de satisfação de consumidores habituais da marca após a concretização da compra dos seus produtos.

Não o bastante, nesta página denominada 'experiência', a empresa utiliza do título 'Histórias de Encantamento' (Figura 3) para atrair os usuários a assistirem a um vídeo cujo conteúdo relata histórias emocionantes e engraçadas que, conforme o próprio vídeo, só podem ser vivenciadas por quem consome em suas lojas, uma vez que se utilizam da frase "só acontecem nas lojas Reserva". Tal ação reforça a ideia da estratégia do marketing experiencial apresentada por Schimitt (1999), Prahalad e Ramaswany (2000), Poulsson e Kale (2004) e Sousa Júnior et al. (2018) de que a experiência deve ser vendida como uma vivência única e totalmente pessoal.

\section{HISTÓRIAS DE ENCANTAMENTO}

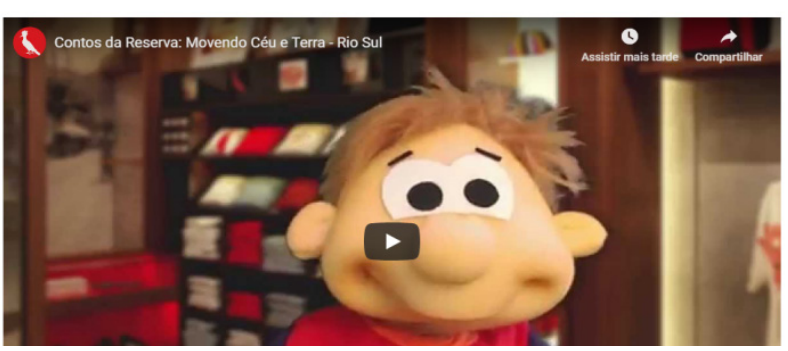

Figura 3. Experiência no site da Reserva

Fonte: Reserva (2019a).

Além desta estratégia de individualidade experiencial, a empresa utiliza de outros atributos para reforçar seus valores a partir da experiência que tentam proporcionar a seus consumidores através do site. Outra das estratégias de marketing experiencial é fazer relação apelo com o emocional dos indivíduos, como apresentado, por exemplo, por Gupta e Vajic (2000) e Barbosa et al. (2011), ao trazer a ideia de família, diálogo - estabelecendo um relacionamento mútuo -, e conforto - uma vez que remete a utilização das suas peças a como se os clientes estivessem em casa, como observado na Figura 4.

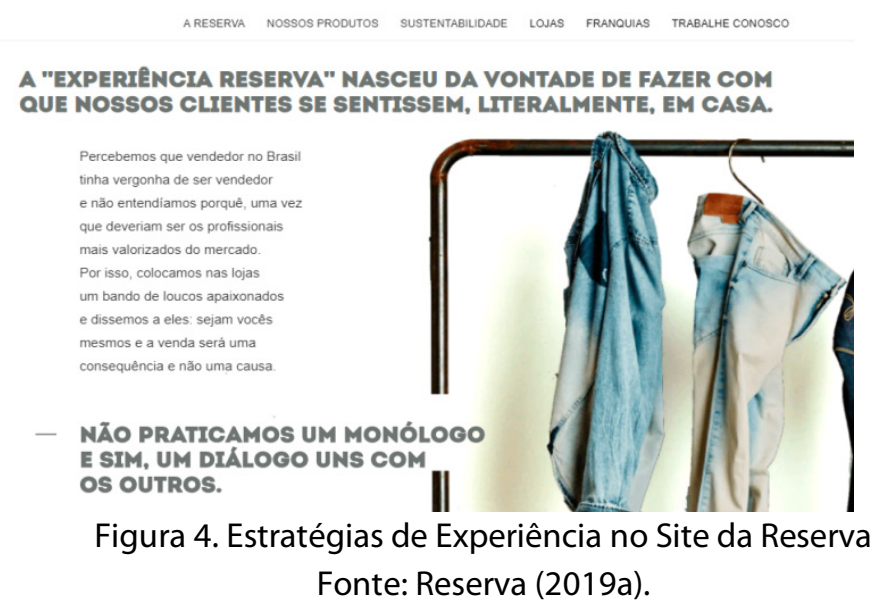

Para além deste exemplo, um breve passeio pelo site apresenta diversas outras frases de impacto que tendem a criar, nos usuários, sentimentos de aproximação e identificação, capazes de gerar o interesse pela vivência da experiência de compra e utilização do estilo de vida proposto em seus produtos. Alguns exemplos de frases são: "Que seja Reserva, Sempre.", "O afeto move montanhas", "A Reserva não é uma empresa que 
vende roupas pra pessoas e sim, uma empresa de pessoas que vendem roupas", "Somos uma família", "Não praticamos um monólogo e sim, um diálogo uns com os outros", "Ser feliz nunca sai de moda", "Acreditamos que através das nossas campanhas mudaremos o mundo".

Nas redes sociais digitais não é diferente, a marca conta com mais 660 mil seguidores em seu perfil oficial no Instagram, e já fez mais de 6.400 publicações. Nesta plataforma, durante o período de coleta de dados deste artigo, a empresa realizou postagens com diversos apelos promocionais, dentre eles, principalmente, investindo no conceito da diversidade. Frases como "Camisetas inspiradas no astral que queremos espalhar por aí", "é sobre muita alegria e amor", "para todos os momentos, não importal qual a ocasião", a empresa apresentou suas coleções de produtos ressaltando a sua imagem e valores, atrelando-os à temática da diversidade, ao conceito de família e amizade e, em especial, nos últimos meses, começou a trazer estratégias de experiência emocional ao resgatar memórias dos consumidores por meio de promoção de produtos com temática do grupo musical Mamonas Assassinas e do personagem de desenho infantil Gato Felix. Essa abordagem nostálgica faz parte da utilização das emoções dentro do contexto do marketing experiencial e pode ser observada nas Figuras 5 e 6 abaixo.
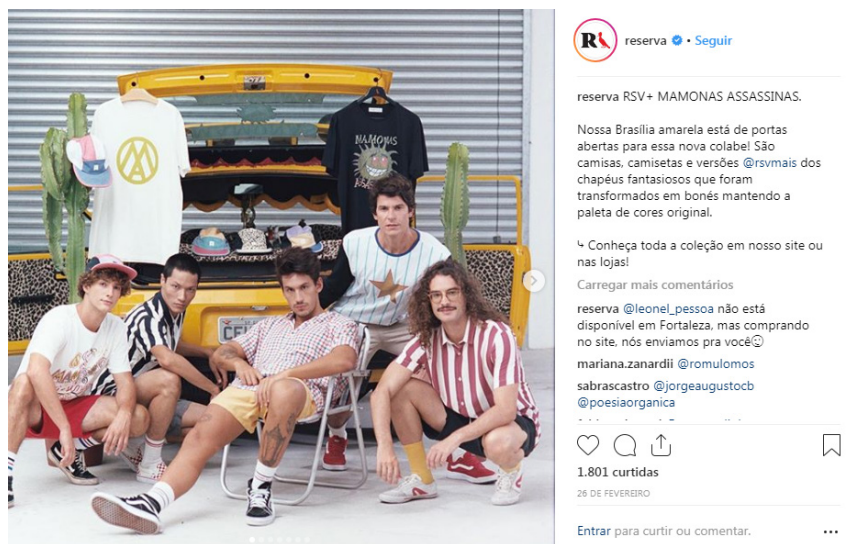

Figura 5. Experiência emocional no Instagram da Reserva Fonte: Reserva (2019b).

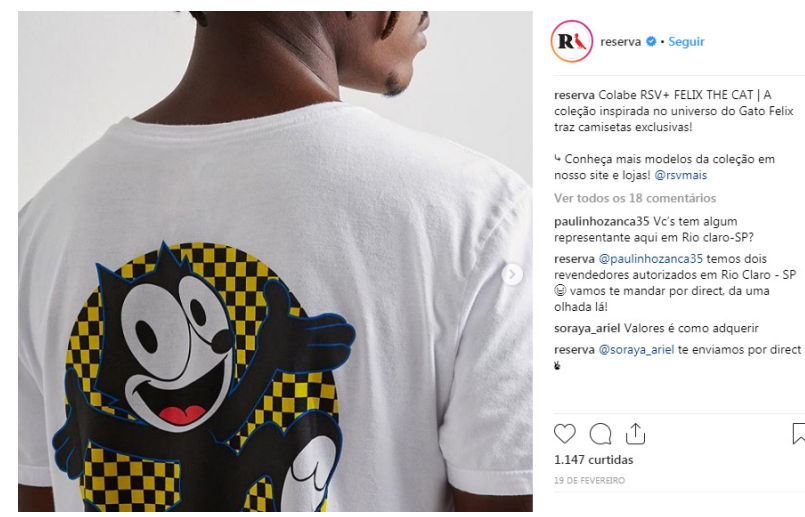

Figura 6. Experiência emocional no Instragram da Reserva Fonte: Reserva (2019b).

No que diz respeito a pagina oficial da empresa no Facebook, a marca contabiliza mais de dois milhões seguidores, e utiliza estratégias mais direcionadas aos posicionamentos adotados no site oficial, com apelos mais sustentáveis e utilizando de frases como "técnicas da estamparia digital, que causa menos impacto ao meio ambiente" e "Confeccionadas com fibras sustentáveis e orgânicas, elas prezam pelo conforto e são perfeitas para o dia a dia". Além dessas, assim como no site, a empresa reforça o posicionamento de 
exclusividade dos seus produtos e vivência de experiências únicas e pessoais, utilizando-se de frases como "que você só vai ver na Reserva", como se pode observar na Figura 7.

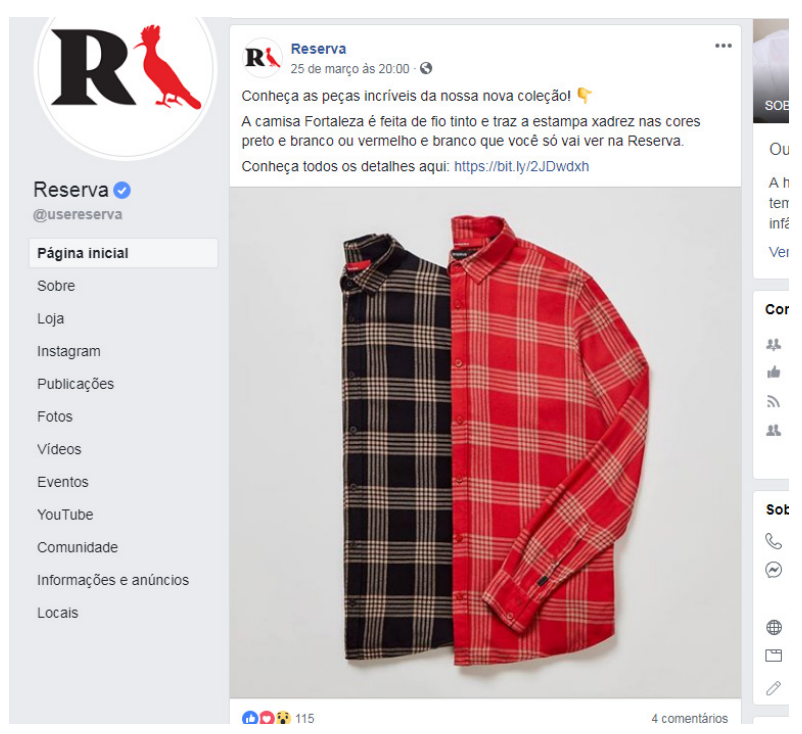

Figura 7. Experiência exclusiva no Facebook da Reserva

Fonte: Reserva (2019c).

Em relação aos feedbacks dos usuários nos perfis oficiais da empresa nas redes sociais virtuais aqui observadas, Facebook e Instagram, é necessário, inicialmente, destacar que a marca apresenta boa interação com os seus usuários, com postagens quase diárias e isso reflete nos números de seguidores (mais de meio milhão no Facebooke mais de dois milhões no Instagram). Esses números podem refletir o papel interativo da marca, bem como as curtidas e os comentários que são direcionados nestes ambientes.

Observou-se que, no Facebook há um engajamento por parte das reações (curtiu, amei, triste etc.), porém poucos comentários nas postagens, sendo estes comentários, quase exclusivamente, de pessoas que demostram interesse pelo produto ofertado ou de pessoas que tiveram alguma decepção com a empresa buscando ter seu problema solucionado - neste ponto, todos os comentários negativos no período coletado foram respondidos pelos perfis oficiais, sendo direcionada a queixa para um diálogo por meio de mensagens privadas. No Instagram, por sua vez, há um número maior de likes e de comentários, positivos, em sua maioria, elogiando a marca, a coleção e/ou o produto ofertado.

\section{CONSIDERAÇÕES FINAIS}

A partir da compreensão de que a nova economia, os novos mercados e as transformações que ocorrem a todo o momento no cenário global afetam diretamente o modo de vida da sociedade, o comportamento do consumidor e as empresas, a busca por estratégias mercadológicas que sejam capazes de compreender os novos cenários mundiais faz-se necessária para que qualquer organização consiga alcançar seus objetivos e atingir o sucesso. Com base nesse pensamento, este estudo se propôs a analisar as estratégias de marketing de experiência adotadas por uma empresa do segmento de vestuário no Brasil.

É notório, entre a literatura acadêmica e o mercado, que a compreensão e o favorecimento de experiências aos consumidores já é realidade como ferramenta estratégica de marketing em empresas de diversos segmentos. As buscas por atender aos desejos e proporcionar envolvimento dos consumidores com as marcas propiciam a utilização deste tipo de estratégia favorecendo não apenas o consumo do bem ou serviço ofertado, mas, também, o consumo da experiência de compra vivenciada pelo indivíduo. 
Conforme observado a partir das análises realizadas neste artigo, apelos emocionais e frases de impacto fortalecem o posicionamento da marca na mente do consumidor e implicam no engajamento dos mesmos para com as marcas. Essa estratégia de reforçar os valores e utilizar elementos em voga na sociedade (como a sustentabilidade, diversidade e nostalgia, na Reserva), auxilia não apenas no favorecimento do engajamento dos consumidores nas mídias digitais oficiais da empresa, mas, também, no relacionamento com seus usuários e consumidores.

É notório que a Reserva trabalha a ideia de experiência a partir de vídeos, imagens e frases de efeito, de modo a tentar atribuir significados e sentidos exclusivos aos seus produtos, o que desperta nos seguidores dos perfis o desejo pela compra não apenas do item isolado, mas da coleção apresentada. Outro ponto relevante é a criação de vínculos afetivos com os usuários, de modo que a experiência passa a ser não apenas da mera utilização da peça de roupa ou acessório, mas de um novo estilo de vida - no caso da Reserva: mais inclusivo, mais sustentável, mais consciente e único.

Assim, fica evidente que o marketing de experiência dentro do segmento de vestuário está relacionado a aspectos como: conceitos, valores, significados e estilo de vida. A frase "só as lojas da Reserva têm", tão utilizada no site e na página oficial do Facebook, refletem o conceito de que a vivência de experiências dentro do ambiente de compra da marca é única e diferenciada.

Diante de todos esses pontos, é possível concluir que o marketing experiencial é uma realidade como estratégia mercadológica e de potencial expansão para novos segmentos e empresas, uma vez que prioriza o novo perfil de consumidor (mais ativo, participante e crítico) e exige das organizações um novo tipo de relacionamento, que extrapola a relação usual e tradicional de compra, e proporciona vivências únicas e experiências diferenciadas - não apenas no momento da compra, mas também no pós-compra -, capazes de criar ou despertar novos significados e conceitos de vida no consumidor.

Como sugestões para futuros estudos, pode-se fazer um estudo netnográfico com a finalidade de analisar o comportamento ou resposta dos usuários e consumidores das marcas que utilizam da estratégia do marketing experiencial nas plataformas on-line; bem como, podem-se fazer estudos quantitativos de caráter descritivo de modo a compreender, de forma mais generalizada, se diferentes empresas apresentam determinados fatores do marketing de experiência, levantados na revisão de literatura, ou se os usuários compreendem as experiências vivenciadas por diferentes empresas como estratégias favoráveis à sua fidelização e envolvimento, por exemplo.

\section{AGRADECIMENTOS}

O autor agradece a CAPES pelos recursos disponibilizados para a realização desta pesquisa.

\section{REFERÊNCIAS}

ABIT. (2018). Setor têxtil 2018: quais as perspectivas e cenários?. Associação Brasileira de Indústria Têxtil. Disponível em: https:/fcem.com.br/noticias/setor-textil-2018-quais-as-perspectivas-ecenarios/\#.WzrWRFVKjIU.

AMA. (2019). Marketing. American Marketing Association. Disponível em: http://www.ama.org

Barbosa, M. L. A., Souza, A. G., Kovacs, M. H. \& Melo, L. S. A. (2011). Gestão da experiência de serviços de hospitalidade: o que a empresa propõe e qual o significado para o consumidor. Observatório de Inovação do Turismo - Revista Acadêmica, 6(2), Rio de Janeiro.

Bezerra, M. G. (2012). Marketing aplicado às Bibliotecas Universitárias. uma revisão bibliográfica. Departamento de Biblioteconomia, Universidade Federal do Rio Grande do Norte, Natal.

Cobra, M. (2011). Marketing básico: uma abordagem brasileira. (4ª ed.) São Paulo: Atlas.

Ferrel, O. C. \& Hartline, M. D. (2006). Estratégia de Marketing. São Paulo: Thompson Learning.

Gupta, S \& Vajic, M. (2000). The contextual and dialectical nature of experience, new service development, creating memorable experiences. Thousand Oaks: SAGE.

Holbrook, M. B. (2000). The millennial consumer in the texts of our times: experience and entertainment. Journal of Macromarketing, 20(2), december. 
Holbrook, M. B. \& Hirschman, E. C. (1982). The experiential aspects of consumption: consumer fantasy, feelings and fun. Journal of Consumer Research, 9(2), 132-140.

IEMI. (2012). Mercado de Vestuário no Brasil. Instituto de Estudos de Marketing Industrial. Disponível em http://www.iemi.com.br/.

IEMI. (2018). Mercado Têxtil. Instituto de Estudos de Marketing Industrial. Disponível em http://www.iemi.com.br/category/txtil/mercado-txtil/.

Kotler, P. \& Keller, K. L. (2012). Administração de Marketing. (14a ed.) São Paulo: Pearson Prentice Hall.

Kozinetz, R. V. (2010). Netnografia: a arma secreta dos profissionais de marketing. Bravdesign.

Las Casas, A. L. (2009). Marketing: conceito, exercícios e casos. (8a ed.) São Paulo: Atlas.

Mattos, G. Z. W. (2011). A utilização das mídias sociais. Facebook e Twitter como ferramenta de marketing no setor de telecomunicações. Trabalho de conclusão de curso, Escola de Administração, Universidade Federal do Rio Grande do Sul, Porto Alegre.

Mesquita, R. (2018). O que é marketing: tudo que você precisa saber sobre o assunto. Rock Content. Disponível em https://rockcontent.com/blog/o-que-e-marketing/.

Meusucesso.com. (2016). Pica-pau, moda e marca: o que eles têm em comum?. Disponível em https://meusucesso.com/noticias/por-que-o-pica-pau-1204/.

O'Shaughnessy, J. \& O'Shaughnessy, N. J. (2002). Marketing, the consumer society and hedonism. European Journal of Marketing, v. 36, n. 5/6, p. 524-547.

Poulsson, S.; Kale, S. (2004). The Experience Economy and Commercial Experiences. The Marketing Review, 4(3), 267-277.

Prahalad, C. K.; Ramaswany, V. (2000). Mon client est très competent!. L'Éxpansion Management Review, 31-40, september.

Reserva. (2019a). Institucional. Disponível em: https://www.usereserva.com/usereserva/institucional/.

Reserva. (2019b). Reserva - Perfil Oficial. Disponível em: https://www.instagram.com/reserva/?hl=pt-br/.

Reserva. (2019c). Reserva - Página Oficial. Disponível em: https://www.facebook.com/usereserva/

Schmitt, B. H. (1999). Experiential marketing. How to get customers to sense, feel, think, act, and relate to your company and brands. New York, NY: Free Press.

Silva Junior, A. S., Vieira, N. S. \& Feitosa, M. G. G. (2012). A relação entre cultura organizacional e aprendizagem dos integrantes de organizações clientes de consultorias. um ensaio teórico sob a luz da teoria de Argyris. Simpósio de Excelência em Gestão e Tecnologia - SEGeT.

Sousa Júnior, J. H., Silva, B. G. F., Barbosa, M. L. A., Melo, F. V. S. \& Farias, S. A. (2018). Marketing de experiencia en el sector de servicios: un estudio de caso en un museo interactivo. Revista Caribeña de Ciencias Sociales. 